\title{
Description of larval instars of Mystrophorus formicaeformis Ruthe (Hymenoptera: Dryinidae)
}

\author{
A. GUGLIELMINO ${ }^{1,3} \&$ C. BÜCKLE ${ }^{2}$ \\ ${ }^{1}$ Dipartimento di Protezione delle Piante, Università della Tuscia, 01100 Viterbo, Italy \\ ${ }^{2}$ Neckarhalde 48, D-72070 Tübingen, Germany \\ ${ }^{3}$ Corresponding author.E-mail:guglielm@unitus.it
}

\begin{abstract}
The last immature stage and the mature larva of Mystrophorus formicaeformis Ruthe are described for the first time. The affinities of both immature and mature larvae of $M$. formicaeformis and corresponding instars of other subfamilies are respectively discussed.
\end{abstract}

Key words: Bocchinae, Cicadomorpha, Fulgoromorpha, postembryonic development, morphology

\section{Introduction}

Dryinidae (Hymenoptera: Chrysidoidea) are parasitoids of leafhoppers, planthoppers and treehoppers (Hemiptera: Auchenorrhyncha). Their biology is insufficiently known. Also little is known about the relationships between them and their hosts, their postembryonic development, their feeding habits and their larval morphology and anatomy. At present, hosts of few taxa belonging to only five subfamilies (Anteoninae, Aphelopinae, Bocchinae, Dryininae and Gonatopodinae) are known, whereas there is no information on host relationships in the other subfamilies (Apoaphelopinae, Apodryininae, Conganteoninae, Palaeoanteoninae, Plesiodryininae, Ponomarenkoinae, Transdryininae).

The subfamily Bocchinae includes three genera: Bocchus Ashmead 1893, Mirodryinus Ponomarenko 1972 and Mystrophorus Förster 1856. Bocchus is a holarctic genus, whose hosts belong to Caliscelidae and Tropiduchidae (Fulgoromorpha). Mirodryinus and Mystrophorus have a palaearctic distribution and parasitize Cicadellidae of the subfamily Deltocephalinae (Cicadomorpha). Mirodryinus includes species developing on Opsius Fieber 1866 (Opsiini). Mystrophorus species are known to parasitize Diplocolenus Ribaut 1946 (Paralimnini) (Guglielmino \& Olmi 1997, 2007; Ponomarenko 2000). An old record of Deltocephalus sp. (Haupt 1938), related to Mystrophorus formicaeformis Ruthe 1859, is unclear.

At present the postembryonic development of Bocchinae is insufficiently known. There are few data on the immature and mature larvae of Bocchus mirabilis (Perkins 1905) (Fenton, 1918b: as Phorbas mirabilis (Perkins)) and a partial description of the immature larva of Mystrophorus formicaeformis and M. apterus Ponomarenko (Ponomarenko 1975; 2000).

In recent years, Mystrophorus formicaeformis was extensively reared by the authors, resulting in a better knowledge of larval stages. In the present paper detailed descriptions of the external morphology of the last immature stage and the mature larva of Mystrophorus formicaeformis are presented, with the aim to provide larval characters useful for systematic studies on Dryinidae.

\section{Material and methods}

Parasitized leafhoppers were collected between Assergi and Campo Imperatore (Gran Sasso, Abruzzo, Italy) 